\title{
Generating evidence for health policy in challenging settings: lessons learned from four prevention of mother-to-child transmission of HIV implementation research studies in Nigeria
}

\author{
Nadia A. Sam-Agudu ${ }^{1,2^{*}}$, Muktar H. Aliyu ${ }^{3,4}$, Olusegun A. Adeyemi ${ }^{5,1}$, Frank Oronsaye ${ }^{6}$, Bolanle Oyeledun ${ }^{6}$,
} Amaka G. Ogidi ${ }^{7}$ and Echezona E. Ezeanolue $e^{8,9}$

\begin{abstract}
Background: Implementation research (IR) facilitates health systems strengthening and optimal patient outcomes by generating evidence for scale-up of efficacious strategies in context. Thus, difficulties in generating IR evidence, particularly in limited-resource settings with wide disease prevention and treatment gaps, need to be anticipated and addressed. Nigeria is a priority country for the prevention of mother-to-child transmission of HIV (PMTCT). This paper analyses the experiences of four PMTCT IR studies in Nigeria, and proffers solutions to major challenges encountered during implementation.

Studies included and findings: Multicentre PMTCT IR studies conducted in Nigeria during the Global Plan's assessment period (2011 to 2015) were included. Four studies were identified, namely The Baby Shower Trial, Optimizing PMTCT, MoMent and Lafiyan Jikin Mata. Major common challenges encountered were categorised as 'External' (beyond the control of study teams) and 'Internal' (amenable to rectification by study teams).

External challenges included healthcare worker strikes and turnover, acts and threats of ethnic and political violence and terrorism, and multiplicity of required local ethical reviews. Internal challenges included limited research capacity among study staff, research staff turnover and travel restrictions hindering study site visits. Deliberate research capacity-building was provided to study staff through multiple opportunities before and during study implementation. Post-study employment opportunities and pathways for further research career-building are suggested as incentives for study staff retention. Engagement of study community-resident personnel minimised research staff turnover in violence-prone areas.

Conclusions: The IR environment in Nigeria is extremely diverse and challenging, yet, with local experience and anticipatory planning, innovative solutions can be implemented to modulate internal challenges. Issues still remain with healthcare worker strikes and often unpredictable insecurity. There is a dire need for cooperation between institutional review boards across Nigeria in order to minimise the multiplicity of reviews for multicentre studies. External challenges need to be addressed by high-level stakeholders, given Nigeria's crucial regional and global position in the fight against the HIV epidemic.
\end{abstract}

Keywords: HIV, PMTCT, Implementation research, Implementation science, Health systems research, Nigeria

\footnotetext{
* Correspondence: nsamagudu@ihvnigeria.org

'International Research Center of Excellence, Institute of Human Virology Nigeria, Abuja, Nigeria

${ }^{2}$ Division of Epidemiology and Prevention, Institute of Human Virology, University of Maryland School of Medicine, Baltimore, MD, United States of America

Full list of author information is available at the end of the article
}

(c) The Author(s). 2018 Open Access This article is distributed under the terms of the Creative Commons Attribution 4.0 International License (http://creativecommons.org/licenses/by/4.0/), which permits unrestricted use, distribution, and reproduction in any medium, provided you give appropriate credit to the original author(s) and the source, provide a link to the Creative Commons license, and indicate if changes were made. The Creative Commons Public Domain Dedication waiver (http://creativecommons.org/publicdomain/zero/1.0/) applies to the data made available in this article, unless otherwise stated. 


\section{Background}

The Global Plan towards the elimination of new HIV infections among children by 2015 and keeping their mothers alive ('Global Plan') prioritised 21 African countries for the reduction of new child HIV infections by 90\% between 2011 and 2015 [1]. Key to the achievement of these goals is a sequential cascade of multiple maternal and infant services that together constitute a comprehensive, maximally effective prevention of mother-to-child transmission of HIV (PMTCT) programme [2]. Another global HIV initiative, the UNAIDS' 90-90-90 programme, aims to achieve specific targets by 2020 , namely that $90 \%$ of all people living with HIV will know their HIV status, that $90 \%$ of all those diagnosed with HIV will receive sustained antiretroviral therapy (ART), and that $90 \%$ of all people receiving ART will have viral suppression [3]. The 90-90-90 initiative seeks to end the HIV epidemic by "bringing HIV treatment to all who need it" [3].

Nigeria has some of the widest gaps and lowest achievements among the 21 Global Plan priority countries. In the Global Plan's 2011 to 2015 performance period, Nigeria was able to reduce new child infections by only $21 \%(52,000$ to 41,000$)$, and dropped its final vertical transmission rate by only $8 \%$ ( $31 \%$ to $23 \%$ ) [4-6]. Additionally, early infant diagnosis uptake by 2 months of age only marginally increased, from approximately $3 \%$ [7] to 9\% [5]. Finally, ART coverage among pregnant Nigerian women made a modest improvement from $13 \%$ in 2009 [6] to $30 \%$ in 2015 [5]. These persistently sub-target achievements are complicated by multiple factors, including the country's large population [8], sizeable geographic expanse [9] and the highly ethnically diverse population [10].

Nigeria is in dire need of public health strategies amenable to local adaptation, contextual application and scale-up to improve the country's PMTCT performance. Implementation research (IR) is defined as "the scientific study of methods to promote the systematic uptake of clinical research findings and other evidence-based practices into routine practice, and hence to improve the quality (effectiveness, reliability, safety, appropriateness, equity, efficiency) of health care" [11]. IR is therefore a valuable tool for generating and applying evidence towards health system improvements. The per-capita quantity and quality of IR and other PMTCT/HIV research evidence generated and applied in Nigeria - and in the West and Central African region for that matter have been low compared to other African countries and regions [12-14]. Reasons for this sub-optimal research environment include poor local research funding, infrastructure and capacity, poor integration of services, and a lack of mechanisms for putting research into practice [12, 15]. Given Nigeria's persistent challenges with its PMTCT programme, it is especially important for quality, locally relevant IR evidence to be generated to advance the PMTCT agenda.

The objective of this paper is to consolidate and present in-country IR experiences for PMTCT IR studies conducted during the Global Plan performance period in different regions of Nigeria. In addition to being relevant to Global Plan goals, each IR study directly or indirectly addressed one or more of the UNAIDS' 90-90-90 targets as a primary or secondary objective. The consolidated data presented here will provide insight into the most common and pervasive challenges encountered by each or all profiled studies. Ultimately, the paper aims to improve the understanding of the difficult research environment in which the local evidence most needed to facilitate Nigeria's PMTCT agenda has to be generated.

\section{Methods}

\section{Profiles of studies included}

Multicentre PMTCT IR studies, initiated and/or completed in Nigeria at any time during the Global Plan's 2011 to 2015 period, conveniently defined as January 1, 2011, to December 31, 2015, and with patient follow-up and data analysis for primary outcomes completed by December 31, 2016, were included in the review.

Studies that did not meet all three of the selection criteria were excluded. Searches were conducted within the United States National Institutes of Health's (NIH's) Research Portfolio Online Reporting Tool (RePORTER) and online clinical trials registries (Clinicaltrials.gov, WHO's International Clinical Trials platform and the Pan-African Clinical Trials Registry) as well as through the Nigeria Implementation Science Alliance (NISA) network. NISA is a collaborative alliance between local implementing partners, researchers, academia and policymakers in Nigeria, and is committed to identifying, evaluating and disseminating implementation science evidence in-country [15]. Finally, we explored relevant online bibliographic databases and websites (PubMED, Ovid MEDLINE, Web of Science) for pertinent articles published in English language that met the criteria for the following MeSH search terms: "PMTCT", "HIV/AIDS", "implementation science", "implementation research", "Nigeria", and "research". Various combinations of the terms were also employed.

Four distinct studies were identified for inclusion in this joint report; they were all multisite prospective IR studies focusing on PMTCT in Nigeria during the Global Plan performance period. The Baby Shower Trial and the Optimizing PMTCT study were funded by the United States' NIH [16-19]; MoMent [20-22] and the Lafiyan Jikin Mata (Hausa language for 'Excellent health for mothers') (LJM) study [23, 24] were funded by WHO through the Integrating and Scaling up PMTCT through 
Implementation Research (INSPIRE) grant from Global Affairs Canada [25, 26].

After consenting to contributing to this paper, Principal Investigators for all four studies were sent a survey document by email. The survey document included a section for completing study profiles and posed openended questions about study experiences and internal and external challenges and solutions. Additional comments and experiences not covered by the survey were also invited. Principal Investigators ultimately completed these surveys in collaboration with their respective project coordinators where applicable/available. Data collected from each study were collated and organised into the manuscript according to the internal and external challenge/solution themes. Where available, previous publications served as additional sources of data.

\section{Geographical settings of studies included}

All four studies were conducted exclusively in Nigeria across five states and the Federal Capital Territory (FCT), spanning three of the country's six geopolitical zones (Fig. 1). Study settings involved both urban and rural communities; the Baby Shower and LJM trials involved a mix of urban and rural study sites, whereas MoMent and the Optimizing PMTCT studies were largely rural. In 2014, HIV prevalence among pregnant women in all six study states/territories were as follows:
Benue 15.4\% (highest in Nigeria), Enugu 4.9\%, FCT 5. $8 \%$, Kaduna 2.2\%, Nasarawa $6.3 \%$ and Niger $1.7 \%$ [27]. Although contiguously located in the North-Central zone, major ethnic groups and languages differ fairly widely in Benue (Tiv and Idoma) [28], FCT (Gbagyi, Fulani, Hausa) [29], Nasarawa (Agatu, Basa, Eggon, Hausa) [30] and Niger (Nupe, Gbagyi, Hausa) [31]. Kaduna State in the North-West zone has a majority composed of Gbayi, Hausa and Fulani ethnic groups [32], and Enugu State in South-East is of largely Igbo ethnicity [33]. In terms of religion, Niger $(78.6 \%$ vs. $17.7 \%)$ state has a principally Muslim population (vs. Christian population, respectively), as opposed to FCT (27.4\% vs. $68.0 \%)$ and Enugu (1.0\% vs. 97.3\%), which have a principally Christian population [34]. Kaduna ( $54.2 \%$ vs. $45.9 \%)$ and Nasarawa ( $41.4 \%$ vs. $56.7 \%)$ states have more similar distributions of Muslims versus Christians [34].

\section{Data collection and organisation}

In addition to published protocol and outcomes papers, data sources included Principal Investigators and Study Coordinators of each of the four IR studies. The experiences described highlight major challenges common to study implementation for all the studies, and unique challenges significant enough to warrant mention. Study implementation challenges were thematically categorised under 'External' and 'Internal' subgroupings. External

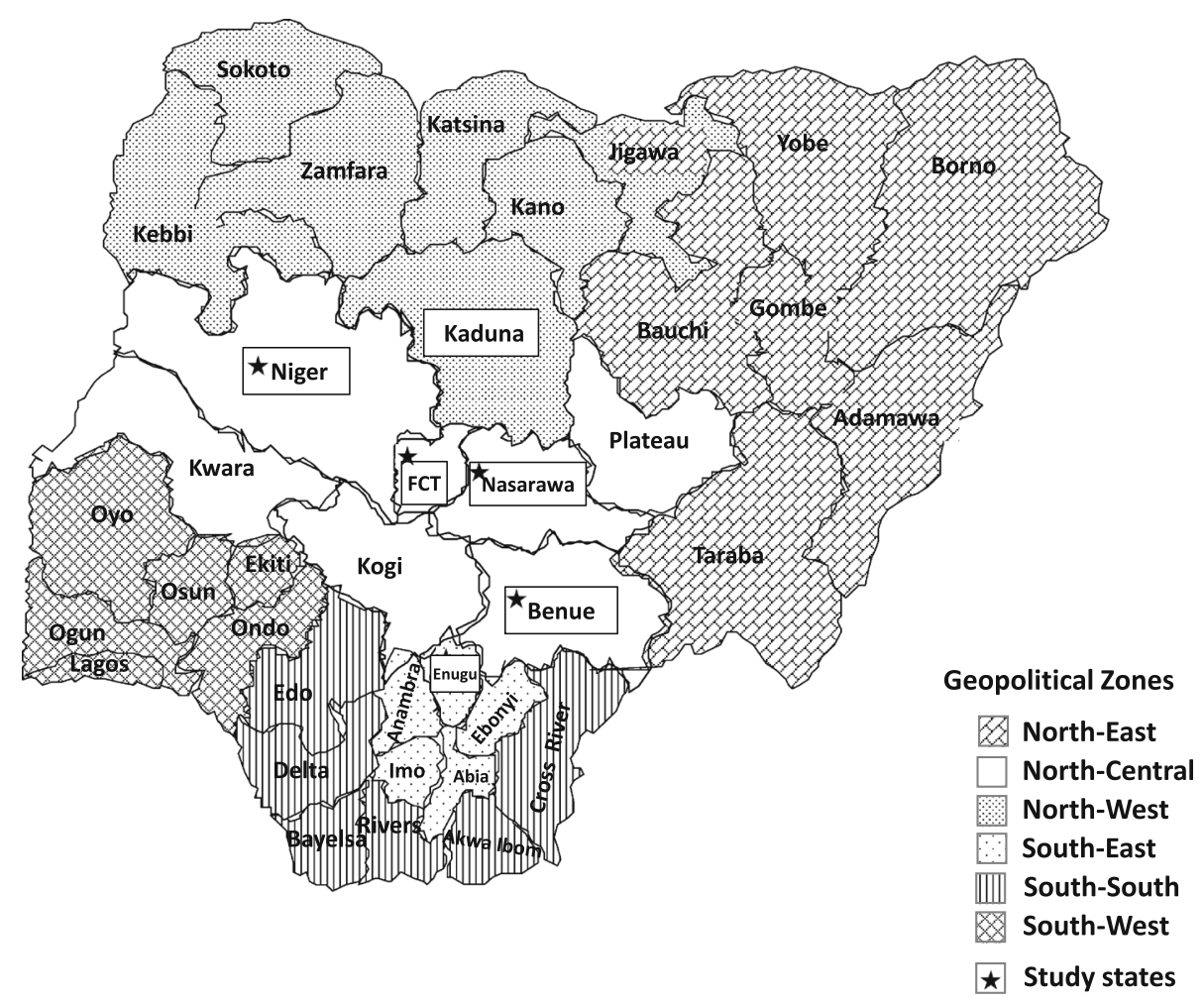

Fig. 1 Geographical scope of the four PMTCT implementation research studies in Nigeria 
challenges denote those that were beyond the control of the study teams, namely challenges that needed significant structural, political or other changes in order to be minimised or rectified. Internal challenges are those most amenable to rectification by the study implementation team itself; in other words, challenges easier to control. The details and impact of these challenges are addressed under each theme. For each major challenge encountered, an implemented and/or suggested solution is described.

\section{Results}

Table 1 presents profiles for all four studies, which were conducted in a period spanning 2012 to 2017. Three studies were randomised controlled trials, and one (MoMent) was a prospective cohort study. Each study's objectives and outcome measures were relevant to at least one of the three 90s of the 90-90-90 initiative. A total of 4431 pregnant women (including 1449 living with HIV) and 1260 HIV-exposed infants were formally enrolled in the four studies. Additionally, the Baby Shower Trial enrolled 2498 male partners. Primary and key secondary outcome results from all four studies have been published, with largely positive findings regarding impact of the interventions tested [18, 19, 21, 22, 24, 35-37].

\section{External challenges}

\section{Healthcare worker (HCW) strikes}

Industrial strike actions by organised labour unions are common in Nigeria; these strikes took root in the colonial period of the 1930s to 1950s but persisted through the post-independence 1970s to present times [38, 39]. HCW strikes are unfortunately a notable subset of strike actions in Nigeria, causing shutdowns and lockdowns of healthcare facilities and intimidation by striking HCWs of colleagues who choose to continue to provide services in spite of the strike.

Exposure to, and impact of, $\mathrm{HCW}$ strikes were most notable for the INSPIRE studies [40]. During MoMent's and LJM's 5-year study period, there was an annual average of three state and/or national-level HCW strikes directly affecting the studies. The duration of the strikes ranged between 5 days and $3 \frac{1}{2}$ months. The major reason for these HCW strikes was unpaid and/or irregular salary payments, with some employees not being paid for up to 8 months. Ultimately, study implementation and participants' access to study sites were compromised. LJM sites were exposed to HCW strikes for a median proportion of $18.8 \%$ (IQR $0.0-40.0 \%$ ) of the sitelevel study implementation period; individual study participants were exposed to HCW strikes for a median of 22 . $5 \%(0.0-100.0 \%)$ of their study enrolment period. Clearly, retention outcome measures (which are dependent on missed or made participant appointments) were also affected. Invariably, recruitment was up to $50 \%$ less efficient, and overall timelines for the INSPIRE studies were significantly delayed, necessitating multiple requests for no-cost extensions from funders.

\section{HCW turnover}

$\mathrm{HCW}$ turnover occurred in two main ways; first, HCWs left their jobs due to better opportunities elsewhere, or were re-posted during often impromptu reshuffles of state and/or local government workforce. The latter practice largely affected state government-owned study sites that were secondary or primary-level facilities, and not federally run tertiary facilities. HCWs at a study facility would be promptly transferred to work at a different facility often in a completely different district; their replacement would come from a different facility and not necessarily have the same level of experience or motivation as the deployed worker. State Ministries of Health engaged in this workforce reshuffling under state and local government practice, a prerequisite for every HCW engaged. The purpose is to ensure that human resources for health are equitably distributed across all districts and sub-districts in local government areas. However, this is counterproductive in study settings, as consistency of study-trained HCWs is a major requirement in protocol compliance and data quality.

Reshuffling of state-employed HCWs occurred once in each study state during LJM and MoMent implementation. For the LJM study, 15 out of 16 study facilities in Kaduna experienced transfer of one or both study nurses in the course of the study. Similarly, at least $40 \%$ of the study facilities in Benue experienced transfer of LJM study nurses. This reshuffling practice often led to abrupt disruption of study implementation, especially at intervention sites, where new and/or intensified strategies were being implemented by/with HCWs. Study orientation and training on tools therefore had to be conducted afresh for transferred-in and/or newly hired HCWs.

Clinic staff deployments were not that much of a concern for the Optimizing PMTCT study. Due to prior experience with high staff turnover in the first year of their PEPFAR (President's Emergency Plan for AIDS Relief) programme, the local implementing partner (Friends in Global Health Nigeria) included a clause in its memorandum of understanding with the Niger state government in subsequent years that required prior consultation before a trained health worker was deployed to a different facility.

\section{Acts and threats of ethnic and politically motivated violence and terrorism}

Security in Nigeria became an increasing concern after the intensification of Boko Haram's local activities in 2009. The areas most affected by Boko Haram are in northern Nigeria, specifically in the North-East, North-Central, and 


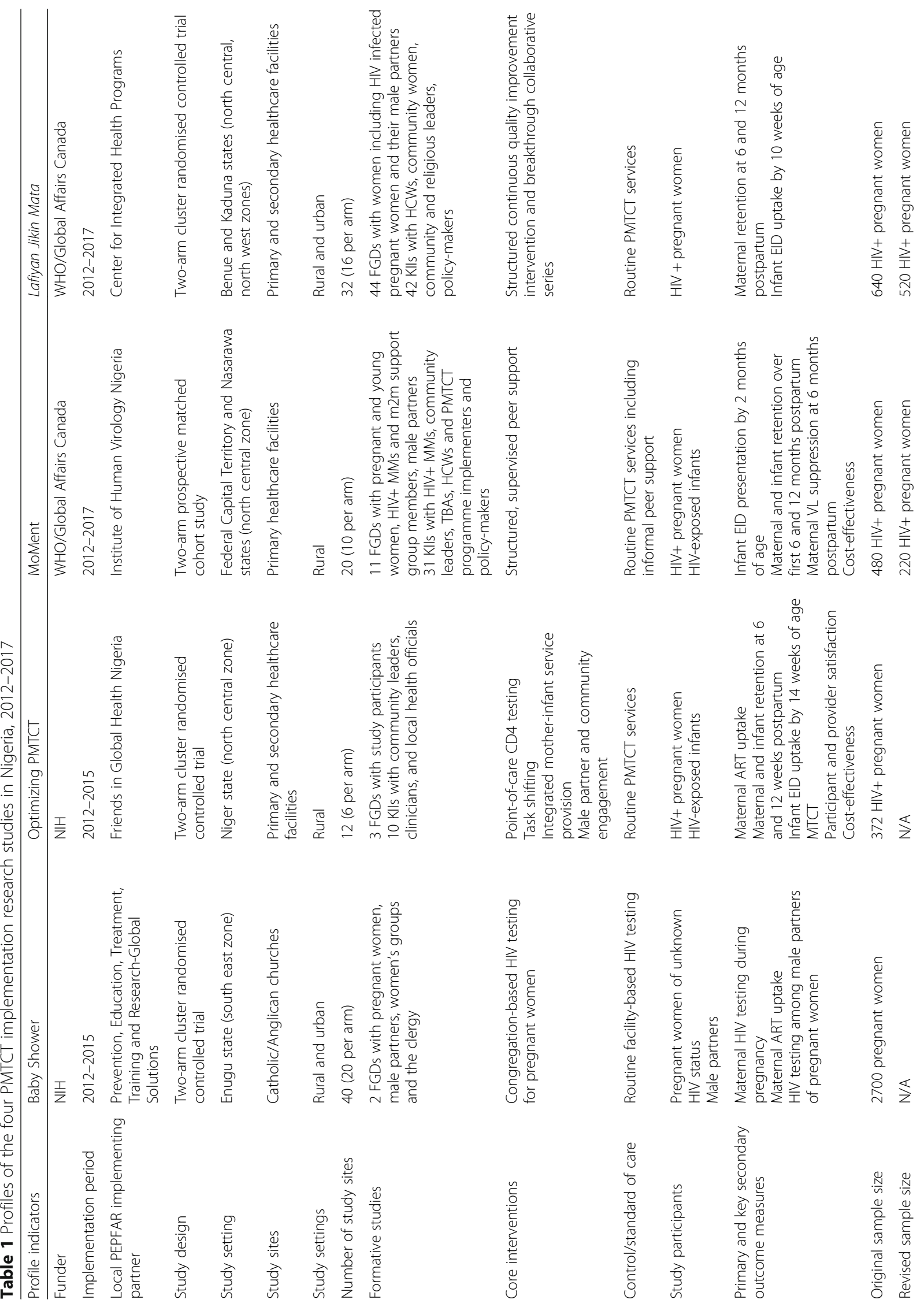




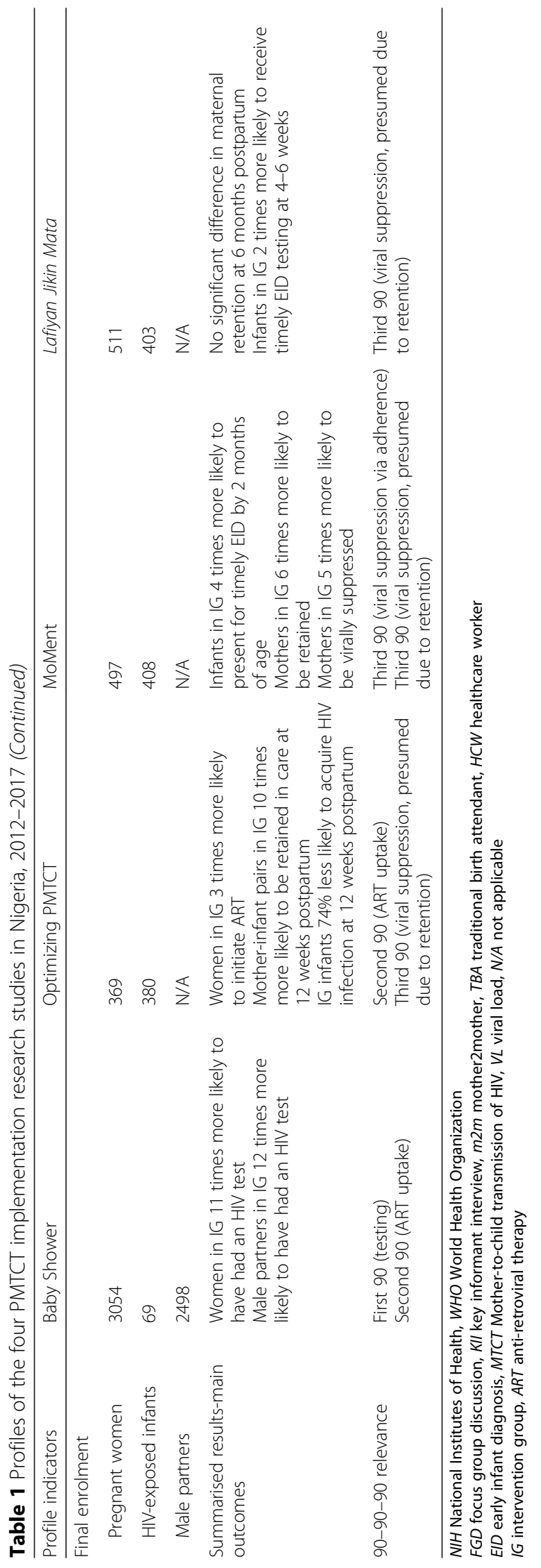


North-West. Ultimately, the INSPIRE studies were most affected by threats or acts of Boko Haram terrorism at their study sites. This translated into significant disruptions in the lives of affected HCWs, participants and research staff, in addition to travel restrictions for supervising research staff from Central Offices in the capital city Abuja.

Ethnic violence affecting the studies occurred largely around the border areas and within Nasarawa and Benue States, again impacting the INSPIRE studies specifically. This type of conflict was highly unpredictable. Some site-based study staff had to be transferred to work at other sites due to ethnically related threats of violence. Other staff who stayed in violence-prone areas remained under threat of violence along with their families. One MoMent study site had to be replaced due to constant threat of ethnic violence and extremely poor participant recruitment.

All four studies were affected by restricted movement during presidential and gubernatorial elections affecting the entire country or specific states, respectively, due to fear of, or actual violence or unrest.

\section{Multiplicity of local ethical review applications}

Ethical review and oversight for research studies is critical for establishing and maintaining adequate protection for study participants. Ethical oversight from local Institutional Review Boards (IRBs) also ensures that studies are implemented in a manner that takes the local context into consideration, including norms, values and special vulnerabilities. This is important for IR, which is expected to be highly context-specific. The Nigerian Code of Health Research Ethics states that a study involving more than three sites should be reviewed by the National Health Research Ethics Committee (NHREC) [41], presumably to reduce the need for approvals from multiple IRBs at the state or study site level. This option is especially important for IR studies, which typically require multiple sites. There is, however, little specific guidance given by NHREC on coordinated ethical approvals between itself and other in-country IRBs. This deficiency affected the four IR studies, since study teams that had applied for and received NHREC approval were still required by some state institutions and healthcare facilities to additionally apply for full ethical review prior to initiating enrolment in their respective jurisdictions. This resulted in a complicated ethical application process that, being largely paper-based, worsened delays in study implementation. The Optimizing PMTCT study sites were all owned by the Niger state government, which did not have a standing IRB, so NHREC approval was considered sufficient. The Niger state government, however, had to provide written approval for the study to proceed.

\section{Internal challenges}

Lack of research capacity and experience among study staff Competent, experienced research staff are invaluable to the quality and timeliness of study implementation and the quality and validity of data generated. Due to the relative lack of large, prospective, well-funded studies and research consortia in Nigeria [12], it is challenging to find well-trained, experienced research staff for IR. As experienced by all four studies, available staff for these positions are often recent graduates and/or health workers looking to change careers or to broaden their research experience. Even so, these individuals' research experience was limited mostly to short-duration, crosssectional knowledge-attitude-practice studies. Thus, knowledge and expertise in research administration and study implementation, including application for and renewal of IRB approvals, informed consent, standard operating procedures, research data collection, validation, cleaning and storage, and preparation of financial and progress reports, were quite limited among Nigerian study staff. As such, large prospective studies such as the four described in this paper face constraints in recruiting competent, experienced research staff.

\section{Research staff turnover}

The turnover of these staff was also high, because once trained and experienced in research and project management, the staff became more attractive to other organisations. Some staff were recruited for more lucrative local jobs, more often in public health than in research, while some succeeded in gaining admission into educational programmes abroad. Additionally, the relative dearth of experienced research staff meant that less competent staff with little or no interest in research were sometimes the only choices for recruitment. Such personnel would leave as higher-paying job opportunities became available, regardless of the learning opportunities with the IR projects. Finally, the relatively sparse research environment provided limited opportunities for continued/stable employment. Therefore, as IR studies neared completion, some staff left prematurely to find more permanent employment opportunities.

\section{Travel restrictions resulting from security issues}

Study staff were often restricted from travelling to study sites experiencing ongoing violence or threats of violence. During these uncertain times, local staff were able to present to work during peaceful/stable periods, yet centrally located staff in Abuja or in study state capitals were more restricted in travelling to these areas. This situation caused significant interruptions to site supervisory visits provided by centrally located research staff. 


\section{Discussion}

\section{Implemented and suggested solutions} Solutions to external challenges

HCW strikes and turnover are difficult to predict and manage at the team level. Studies reporting impact of HCW strikes on the implementation of prospective trials are lacking. A few studies have reported deleterious effects of Nigerian HCW strikes on patient care, including maternal morbidity and mortality [42, 43], and missed appointments for acute and chronic eye care [44]. Given the significant impact of HCW strikes on participants and projects, all four IR teams developed implementation plans with extra time built-in to allow for these occurrences. Furthermore, study teams prepared funder reports that included detailed narratives of these disruptions, in addition to maintaining a calendar to document the strikes and their duration. These detailed records provide resources for taking these disruptions into consideration as confounding factors, if necessary, during statistical analysis.

HCW turnover was planned for and/or managed with careful selection of multiple HCWs, where available, to train on study activities. Training and re-orientations were also planned regularly during the studies in order to accommodate newly posted HCWs at study sites. In the case of the Optimizing PMTCT study, lessons learned from prior work in Niger state enabled the adoption of language in memoranda of understanding with governing authorities that made arbitrary staff transfers less likely. While the development of such memoranda of understanding is helpful, the terms and conditions should be honoured by all parties involved for optimal functionality.

Acts or threats of political/ethnic violence and terrorism were a persistent reality, especially for the INSPIRE studies. As in the case of HCW strikes, contingency plans included developing study timelines with extra time built in to accommodate these disruptions. As mentioned previously, study sites exposed to what was deemed as extreme levels of insecurity were replaced in order to preserve cluster size and maintain collection of data to facilitate robust statistical analysis. However, the safety of study staff was the topmost priority. Study coordinators subscribed to and tracked news outlets and networks for the most up-to-date information on the location and extent of insecurity and violence. All staff in the field were contacted when situations arose that could impact their safety.

The multiplicity of local ethical reviews complicated the ethical approval process and caused delays in study timelines. The need for each IRB and government institution in the study communities to be informed and knowledgeable about the study is rational, yet requiring full review and approval from each study site/state IRB made the process tedious and duplicative. A solution to this challenge lies in fostering the ability of local IRBs to communicate and share information with each other, thereby reducing the burden associated with the ethical approval process while ensuring protection of all participants. Similar challenges with multicentre studies in the United States have led to moves to streamline the ethical review process and strengthen the use of centralised systems [45]. In Nigeria, NHREC continues to play a dominant role, but sub-national IRBs still function quite independently and often do not take into consideration ethical approvals obtained from NHREC or elsewhere.

\section{Solutions to internal challenges}

One strategy to counter the relative lack of IR capacity among study staff was to establish IR mentoring before and during active implementation of the studies. For example, a team of junior investigators was selected to work closely with the Principal Investigator during grant writing for the Baby Shower trial. Once the study was funded and in active implementation, the junior investigators served as study coordinators, with each assigned to coordinate activities for a specific study aim. The study as a whole is now used to train upcoming junior investigators on various IR skills. Aside from baseline training, the MoMent study held regularly scheduled IR learning sessions called 'MoMent School' to address preexisting and emerging research skill deficiencies noted during study implementation. Additionally, MoMent supported its junior staff to enroll in online and inperson short research courses offered by local and foreign institutions.

Once available in 2014, the WHO IR toolkit [46] served as a useful reference guide, especially for educating new study staff on IR principles. Sections on 'Introduction and Basic Orientation' and 'Planning and Conducting an IR Project' were especially useful as an introduction for new staff and an adjunct to ongoing field experiences for established staff [46]. Involvement of motivated study staff in writing and presenting abstracts and developing manuscripts has yielded invaluable and sustained capacity-building results. Overall, employment and volunteer opportunities for local staff working on the WHO and NIH studies $[12,47]$ were in themselves IR capacity-building opportunities.

To protect investments made in the training and retraining of research staff, we suggest making retention of trained, experienced and competent research personnel a priority. Several approaches could be used to achieve this, including having these staff absorbed and retained between studies at their local academic/public health/research institutions. This would make it easier to re-assign them to research projects once a new study becomes active. Prioritised hiring of experienced research staff could also be implemented across institutions, using platforms 
such as what NISA offers. Such platforms involving multiple governmental, non-governmental and academic institutions can enable individual organisations to communicate the availability of research staff that are completing a study. These staff would therefore be available for engagement on new or ongoing studies seeking qualified staff. These approaches allow for enhancing capacity among an expanding pool of retained research-experienced staff. As an example, the two core research coordinators from Baby Shower were absorbed by the University of Nigeria into their Research Resource Center, subsequently working on a different study in another state [48]. Additionally, five staff from the MoMent and LJM studies were absorbed into NISA's newly funded Adolescent Coordinated Transition study, currently implemented nationwide [49]. Furthermore, the project coordinator for MoMent was retained after the study and is currently pursuing a $\mathrm{PhD}$ under a Fogarty grant targeting Nigerian trainees [50].

Travel restrictions secondary to threats or acts of violence or unrest hindered the implementation and supervisory activities of all four studies, albeit to different extents. The hiring of qualified community members to work at the study sites was extremely useful in minimising turnover and interruptions in site-level study activities, especially at study sites located in unstable areas. The potential travel restrictions for supervising central staff indicate that locally hired staff in these areas would be required to be highly self-driven and proactive since they may receive fewer supervisory and/or mentoring visits.

Ultimately, if studies fail to document details and perform root cause analyses of their challenges, it will be difficult to understand the issues and to develop impactful solutions. For IR projects, consideration of the hybrid models described by Curran et al. [51] or similar approaches for study design is recommended. The three hybrid effectiveness-implementation models described by Curran et al. [51] encompass a priori approaches to testing strategies and/or documenting events relating to clinical effectiveness and/or study implementation. The four studies discussed here were most consistent with the hybrid Type 1 model, where research staff measured effects of study interventions on defined outcomes while observing and gathering information on study implementation. In effect, 'study implementation diaries' were maintained alongside data collection for interventionrelated outcome measures.

\section{Conclusions}

IR in Nigeria is still in its infancy, and the country continues to face challenges in its quest to contribute to the regional and global body of evidence for HIV and other diseases of public health importance. The major obstacles confronting IR studies in Nigeria include frequent $\mathrm{HCW}$ strikes, high turnover of $\mathrm{HCW}$ and research staff, dearth of experienced research staff, insecurity, and burdensome ethical review processes. Nigeria is a priority country in the Global HIV response its research environment can and has to be improved to facilitate the generation of impactful evidence. Lessons learned from past and future research projects will assist in the development of strategies and policies to foster an enabling environment for IR in Nigeria and similarly challenging settings.

\section{Abbreviations \\ ART: Antiretroviral therapy; FCT: Federal Capital Territory; HCW: Healthcare worker; INSPIRE: Integrating and Scaling up PMTCT through Implementation Research; IR: Implementation Research; IRB: institutional review board; LJM: Lafiyan Jikin Mata; NHREC: National Health Research Ethics Committee; $\mathrm{NIH}$ : National Institutes of Health; NISA: Nigeria Implementation Science Alliance; PMTCT: Prevention of mother-to-child transmission of HIV}

\section{Acknowledgements}

All the Principal Investigators and authors would like to collectively acknowledge the efforts and facilitating support of the PEPFAR implementing partners, State Ministries of Health, healthcare workers, clergy, research and academic staff, and other personnel involved with each of the four studies. Finally, we thank study participants across all four projects; the pregnant women, male partners and their infants, whose cooperation and participation contributed to successful implementation.

\section{Funding}

The authors thank all funders for their financial support, namely The Eunice Kennedy Shriver National Institute of Child Health and Human Development of the NIH (award R01HD075050 to EEE and R01HD075075 to MHA), and Global Affairs Canada and the World Health Organization (INSPIRE awards to $\mathrm{BO}$ and NASA). None of the funding bodies played any role in the design of any of the studies or in the collection, analysis, and interpretation of data and in writing this manuscript.

\section{Availability of data and materials}

Data sharing is not applicable to this article as no datasets were generated for this paper. Rather, already available data was collated and reported.

\section{Disclaimer}

The opinions expressed in this article do not necessarily reflect the views or policies of the National Institutes of Health, the World Health Organization or Global Affairs Canada.

\section{Authors' contributions}

NASA contributed to manuscript concept, data acquisition, collation and interpretation, and drafted and critically reviewed the manuscript. MHA and OAA contributed to data acquisition and interpretation, manuscript writing and critical review of the manuscript. FO, BO and AGO contributed to data acquisition and critical review of the manuscript. EE contributed to manuscript concept, data acquisition and interpretation, manuscript writing and critical review of the manuscript. All authors read and approved the final manuscript.

\section{Ethics approval and consent to participate}

All four studies were approved by the Nigerian National Health Research Ethics Committee. The INSPIRE (MoMent and LJM) studies were also approved by the Ethics Review Committee of the World Health Organization. Additionally, the Baby Shower Trial was approved by the Institutional Review Board (IRB) of the University of Nevada Reno; the Optimizing PMTCT study was approved by the IRB of Vanderbilt University; and MoMent was approved by the IRB of the University of Maryland Baltimore.

Competing interests

The authors declare that they have no competing interests. 


\section{Publisher's Note}

Springer Nature remains neutral with regard to jurisdictional claims in published maps and institutional affiliations.

\begin{abstract}
Author details
${ }^{1}$ International Research Center of Excellence, Institute of Human Virology Nigeria, Abuja, Nigeria. ${ }^{2}$ Division of Epidemiology and Prevention, Institute of Human Virology, University of Maryland School of Medicine, Baltimore, MD, United States of America. ${ }^{3}$ Department of Health Policy, Vanderbilt University Medical Center, Nashville, TN, United States of America. ${ }^{4}$ Vanderbilt Institute for Global Health, Nashville, TN, United States of America. ${ }^{5}$ Department of Epidemiology and Public Health, University of Maryland School of Medicine, Baltimore, MD, United States of America. ${ }^{6}$ Center for Integrated Health Programs, Abuja, Federal Capital Territory, Nigeria. ${ }^{7}$ Research Resource Centre, University of Nigeria Nsukka, Enugu, Nigeria. ${ }^{8}$ HealthySunrise Foundation, Las Vegas, NV, United States of America. ${ }^{9}$ Department of Paediatrics and Child Health, University of Nigeria Nsukka, Enugu, Nigeria.
\end{abstract}

\section{Received: 22 September 2017 Accepted: 2 April 2018}

\section{Published online: 17 April 2018}

\section{References}

1. UNAIDS. The Global Plan towards the elimination of new HIV infections among children by 2015 and keeping their mothers alive, 2011-2015. 2011. Accessed 18 May 2017. http://www.unaids.org/en/media/unaids/ contentassets/documents/unaidspublication/2011/20110609_JC2137_ Global-Plan-Elimination-HIV-Children_en.pdf.

2. Hamilton E, Bossiky B, Ditekemena J, Esiru G, Fwamba F, Goga AE, et al. Using the PMTCT cascade to accelerate achievement of the Global Plan goals. J Acquir Immune Defic Syndr. 2017;75(Suppl 1):S27-s35. https://doi. org/10.1097/qai.0000000000001325.

3. UNAIDS. 90-90-90: An Ambitious Treatment Target to Help End the AIDS Epidemic. 2014. Accessed 18 May 2017. http://www.unaids.org/sites/default/ files/media_asset/90-90-90_en_0.pdf.

4. UNAIDS. Report on the Global AIDS Epidemic. 2016. Accessed 24 May 2017 http://www.unaids.org/sites/default/files/media_asset/20160627_ HIV2016Estimates_1990-2015.xIsx.

5. UNAIDS. On the Fast Track to an AIDS Free Generation: The Incredible Journey of the Global Plan Towards the Elimination of New HIV Infections among Children by 2015 and Keeping Their Mothers Alive. 2016. Accessed 17 Sept 2017. http://emtct-iatt.org/wp-content/uploads/2016/06/ GlobalPlan2016_en.pdf.

6. UNAIDS. 2013 Progress Report on the Global Plan Towards the Elimination of New HIV Infections among Children by 2015 and Keeping Their Mothers Alive. 2013. Accessed 7 May 2017. http://www.unaids.org/en/media/unaids/ contentassets/documents/unaidspublication/2013/20130625_progress_ global_plan_en.pdf.

7. UNAIDS. Progress Report on the Global Plan Towards the Elimination of New HIV Infections among Children and Keeping Their Mothers Alive. 2015. Accessed 24 May 2017. http://www.unaids.org/en/resources/documents/ 2015/JC2774_2015ProgressReport_GlobalPlan.

8. Population Reference Bureau. 2016 World Population Data Sheet: USAID; 2016. Accessed 24 May 2017. http://www.prb.org/Publications/Datasheets/ 2016/2016-world-population-data-sheet.aspx.

9. The World Bank. Land Area (Square Kilometers) Data 2016. Accessed 24 May 2017. http://data.worldbank.org/indicator/AG.LND.TOTL.K2.

10. United States Central Intelligence Agency. The World Factbook: Ethnic Groups 2017. Accessed 24 May 2017. https://www.cia.gov/library/ publications/the-world-factbook/fields/2075.html.

11. Eccles MP, Armstrong D, Baker R, Cleary K, Davies H, Davies S, et al. An implementation research agenda. Implement Sci. 2009;4:18. https://doi.org/ 10.1186/1748-5908-4-18.

12. Sam-Agudu NA, Paintsil E, Aliyu MH, Kwara A, Ogunsola F, Afrane YA, et al. Building sustainable local capacity for global health research in West Africa. Ann Glob Health. 2016;82:1010-25. https://doi.org/10.1016/j.aogh.2016.10.011.

13. Sam-Agudu NA, Folayan MO, Ezeanolue EE. Seeking wider access to HIV testing for adolescents in sub-Saharan Africa. Pediatr Res. 2016;79(6):838-45. https://doi.org/10.1038/pr.2016.28. Epub 2016 Feb 16

14. Irikefe V, Vaidyanathan G, Nordling L, Twahirwa A, Nakkazi E, Monastersky R. Science in Africa: The view from the front line. Nature. 2011;474:556-9. https://doi.org/10.1038/474556a.
15. Ezeanolue EE, Powell BJ, Patel D, Olutola A, Obiefune M, Dakum P, et al. Identifying and prioritizing implementation barriers, gaps, and strategies through the Nigeria Implementation Science Alliance: getting to zero in the prevention of mother-to-child transmission of HIV. J Acquir Immune Defic Syndr. 2016;72:S161-S6. https://doi.org/10.1097/ qai.0000000000001066.

16. Ezeanolue EE, Obiefune MC, Yang W, Obaro SK, Ezeanolue CO, Ogedegbe GG. Comparative effectiveness of congregation- versus clinic-based approach to prevention of mother-to-child HIV transmission: study protocol for a cluster randomized controlled trial. Implement Sci. 2013;8: 62. https://doi.org/10.1186/1748-5908-8-62.

17. Aliyu MH, Blevins M, Audet C, Shepherd BE, Hassan A, Onwujekwe O, et al. Optimizing PMTCT service delivery in rural North-Central Nigeria: protocol and design for a cluster randomized study. Contemp Clin Trials. 2013;36: 187-97. https://doi.org/10.1016/j.cct.2013.06.013.

18. Aliyu MH, Blevins M, Audet CM, Kalish M, Gebi UI, Onwujekwe O, et al. Integrated prevention of mother-to-child HIV transmission services, antiretroviral therapy initiation, and maternal and infant retention in care in rural north-central Nigeria: a cluster-randomised controlled trial. Lancet HIV. 2016;3:e202-11. https://doi.org/10.1016/\$2352-3018(16)00018-7.

19. Ezeanolue EE, Obiefune MC, Ezeanolue CO, Ehiri JE, Osuji A, Ogidi AG, et al. Effect of a congregation-based intervention on uptake of HIV testing and linkage to care in pregnant women in Nigeria (Baby Shower): a cluster randomised trial. Lancet Glob Health. 2015;3:e692-700. https://doi.org/10. 1016/S2214-109X(15)00195-3.

20. Sam-Agudu NA, Cornelius LJ, Okundaye JN, Adeyemi OA, Isah HO, Wiwa OM, et al. The impact of mentor mother programs on PMTCT service uptake and retention-in-care at primary health care facilities in Nigeria: a prospective cohort study (MoMent Nigeria). J Acquir Immune Defic Syndr. 2014;67(Suppl 2):S132-8. https://doi.org/10.1097/QAl. 0000000000000331.

21. Sam-Agudu NA, Ramadhani HO, Isah C, Erekaha S, Fan-Osuala C, Anaba U, et al. The impact of structured mentor mother programs on presentation for early infant diagnosis testing in rural north-central Nigeria: a prospective paired cohort study. J Acquir Immune Defic Syndr. 2017;75(Suppl 2):S182-S9. https://doi.org/10.1097/QAl.0000000000001345.

22. Sam-Agudu NA, Ramadhani HO, Isah C, Anaba U, Erekaha S, Fan-Osuala $C$, et al. The impact of structured mentor mother programs on 6month postpartum retention and viral suppression among HIV-positive women in rural Nigeria: a prospective paired cohort study. J Acquir Immune Defic Syndr. 2017;75(Suppl 2):S173-S81. https://doi.org/10.1097/ QAl.0000000000001346.

23. Oyeledun B, Oronsaye F, Oyelade T, Becquet R, Odoh D, Anyaike C, et al. Increasing retention in care of HIV-positive women in PMTCT services through continuous quality improvement-breakthrough (CQI-BTS) series in primary and secondary health care facilities in Nigeria: a cluster randomized controlled trial. The Lafiyan Jikin Mata Study. J Acquir Immune Defic Syndr. 2014;67(Suppl 2):S125-31. https://doi.org/10.1097/qai.0000000000000320.

24. Oyeledun B, Phillips A, Oronsaye F, Alo OD, Shaffer N, Osibo B, et al. The effect of a continuous quality improvement intervention on retention-in-care at 6 months postpartum in a PMTCT program in northern Nigeria: results of a cluster randomized controlled study. J Acquir Immune Defic Syndr. 2017;75(Suppl 2):S156-s64. https://doi.org/ 10.1097/qai.0000000000001363.

25. Blais P, Hirnschall G, Mason E, Shaffer N, Lipa Z, Baller A, et al. Introducing INSPIRE: an implementation research collaboration between the Department of Foreign Affairs, Trade and Development Canada and the World Health Organization. J Acquir Immune Defic Syndr. 2014;67(Suppl 2): S105-7. https://doi.org/10.1097/QAl.0000000000000357.

26. Rollins N, Chanza H, Chimbwandira F, Eliya M, Nyasulu I, Thom E, et al. Prioritizing the PMTCT implementation research agenda in 3 African countries: INtegrating and Scaling up PMTCT through Implementation REsearch (INSPIRE). J Acquir Immune Defic Syndr. 2014;67(Suppl 2):S108-13. https://doi.org/10.1097/QAl.0000000000000358.

27. National AIDS/STI Control Programme, Federal Ministry of Health Nigeria. Technical Report 2014: National HIV Seroprevalence Sentinel Survey Among Pregnant Women Attending Antenatal Clinics in Nigeria. Abuja: Federal Ministry of Health Nigeria; 2014.

28. Benue State Government. Historical Background of Benue State 2016. Accessed 8 June 2017. http://www.benuestate.gov.ng/about-benue/ historical-background.html. 
29. Federal Capital Territory Administration. FCT Area Councils 2017. Accessed 8 June 2017. http://www.abuja-ng.com/federal-capital-territory.html.

30. Nasarawa State Government. Languages of Nasarawa State 2016. Accessed 8 June 2017. http://www.nasarawastate.gov.ng/languages.php.

31. Niger State Government. About Niger State: Peoples and Culture 2017. Accessed 8 June 2017. http://www.nigerstate.gov.ng/about.php.

32. Kaduna State Government. Kaduna State Demographics 2017. Accessed 8 June 2017. http://kdsg.gov.ng/demographics/.

33. Enugu State Government. About Enugu State 2017. Accessed 8 June 2017. http://enugustate.gov.ng/index.php/elements-devices/.

34. Federal Ministry of Health Nigeria. National HIV \& AIDS and Reproductive Health Survey (NARHS Plus II). 2013. Accessed 7 Apr 2017. http://nascp.gov.ng/ demo/wp-content/uploads/2014/02/NARHS-Plus-2012-Final-18112013.pdf.

35. Pharr JR, Obiefune MC, Ezeanolue CO, Osuji A, Ogidi AG, Gbadamosi S, et al. Linkage to care, early infant diagnosis, and perinatal transmission among infants born to HIV-infected Nigerian mothers: evidence from the Healthy Beginning Initiative. J Acquir Immune Defic Syndr. 2016;72:S154-S60. https://doi.org/10.1097/qai.0000000000001051.

36. Boehmer A, Audet CM, Blevins M, Gebi UI, Wester CW, Vermund SH, et al. Patient and provider satisfaction with a comprehensive strategy to improve prevention of mother-to-child HIV transmission services in rural Nigeria. J Acquir Immune Defic Syndr. 2016;72(Suppl 2):S117-23. https://doi.org/ 10.1097/QAl.0000000000001058.

37. Sam-Agudu NA, Isah C, Fan-Osuala C, Erekaha S, Ramadhani HO, Anaba U, et al. Correlates of facility delivery for rural HIV-positive pregnant women enrolled in the MoMent Nigeria prospective cohort study. BMC Pregnancy Childbirth. 2017;17:227. https://doi.org/10.1186/s12884-017-1417-2.

38. Oseni QM. The Impact of Strike Action on the Achievement of Trade Union Objective. 2012. Accessed 3 June 2017. http://pubs.caritasuni.edu.ng/ download.php?file=projects/2011-2012\%20Projects/IRPM/THE\%20IMPACT \%20OF\%20STRIKE\%20ACTION\%200N\%20THE\%20ACHIEVEMENT\%20 OF\%20TRADE\%20UNION\%200BJECTIVE.pdf.

39. Osabuohien E, Ogunrinola IO. Causes and Effects of Industrial Crises in Nigeria: Some Empirical Clarifications. Labour Law Review. 2007. Accessed 3 June 2017. http://eprints.covenantuniversity.edu.ng/4400/1/Causes\%20 and $\% 20$ Effects\%20Industrial\%20crisis\%20\%20in\%20Nigeria\%3B\%20Some\%20 empirical\%20clarifications\%20NJLIR.pdf.

40. Sam-Agudu NA, Oyeledun B, Adeyemi OA, Bigirimana F, Oronsaye F, Oyelade $T$, et al. The Challenges of Conducting Implementation Research in a Highly Unstable Environment: Experiences from the INSPIRE Nigeria PMTCT Studies. Harare: International Conference on AIDS and STIs in Africa; 2015.

41. National Health Research Ethics Committee of Nigeria. National Code of Health Research Ethics. 2007. Accessed 5 June 2017. https://healthresearchweb.org/ ?action=download\&file=NCHRE\%20Current\%20Version.pdf.

42. Okafor UV, Efetie ER, Onwuekwe I, Uwaezeoke TC. Cerebrovascular accident with quadriplegia following postpartum eclampsia. Acta Anaesthesiol Scand. 2006;50:382-4. https://doi.org/10.1111/j.1399-6576.2006.00920.x

43. Ozumba BC, Nwogu-lkojo EE. Avoidable maternal mortality in Enugu, Nigeria. Public Health. 2008;122:354-60. https://doi.org/10.1016/j.puhe.2007.04.018.

44. Ademola-Popoola DS, Akande TM, Idris A. Patients' assessment of quality of eye care in a Nigerian teaching hospital. Niger Postgrad Med J. 2005;12:145-8.

45. Check DK, Weinfurt KP, Dombeck CB, Kramer JM, Flynn KE. Use of central institutional review boards for multicenter clinical trials in the United States: a review of the literature. Clin Trials. 2013;10:560-7. https://doi.org/10.1177/ 1740774513484393.

46. World Health Organization. Implementation Research Toolkit: Facilitator's Guide 2014. Accessed 25 July 2017. http://apps.who.int/iris/bitstream/10665/ 110523/2/9789241506960_Facilitator_guide_eng.pdf.

47. Newman Owiredu M, Bellare NB, Chakanyuka Musanhu CC, Oyelade TA, Thom EM, Bigirimana F, et al. Building health system capacity through implementation research: experience of INSPIRE-A multi-country PMTCT implementation research project. J Acquir Immune Defic Syndr. 2017; 75(Suppl 2):S240-S7. https://doi.org/10.1097/QAl.0000000000001370.

48. Ezeanolue EE, Gbadamosi SO, Olawepo JO, Iwelunmor J, Sarpong D, Eze C, et al. An mHealth framework to improve birth outcomes in Benue State, Nigeria: a study protocol. JMIR Res Protoc. 2017;6:e100. https://doi.org/10.2196/resprot.7743.
49. Sam-Agudu NA, Pharr JR, Bruno T, Cross CL, Cornelius LJ, Okonkwo P, et al. Adolescent Coordinated Transition (ACT) to improve health outcomes among young people living with HIV in Nigeria: study protocol for a randomized controlled trial. Trials. 2017;18:595. https://doi.org/10.1186/ s13063-017-2347-z.

50. NIH RePORT. Epidemiology Research Training for Public Health Impact in Nigeria (Epi-Nigeria), Principal Investigators M. Charurat and A. Abimiku. 2016. https://projectreporter.nih.gov/project_info_description.cfm?aid= 9437862\&icde $=38701827 \&$ ddparam $=\& d d v a l u e=\& d d s u b=\& c r=4 \& c s b=$ default\&cs=ASC\&pball=.

51. Curran GM, Bauer M, Mittman B, Pyne JM, Stetler C. Effectivenessimplementation hybrid designs: combining elements of clinical effectiveness and implementation research to enhance public health impact. Med Care. 2012;50:217-26. https://doi.org/10.1097/MLR. ob013e3182408812.

\section{Ready to submit your research? Choose BMC and benefit from:}

- fast, convenient online submission

- thorough peer review by experienced researchers in your field

- rapid publication on acceptance

- support for research data, including large and complex data types

- gold Open Access which fosters wider collaboration and increased citations

- maximum visibility for your research: over $100 \mathrm{M}$ website views per year

At BMC, research is always in progress.

Learn more biomedcentral.com/submissions 